\title{
Diagnosis of invasive whitefly species co-occurring on coconut
}

\author{
A. Josephrajkumar ${ }^{1, *}$, Chandrika Mohan ${ }^{1}$, Merin Babu ${ }^{1}$, P. S. Prathibha ${ }^{2}$, \\ Vinayaka Hegde $^{2}$ and V. Krishnakumar ${ }^{1}$ \\ ${ }^{1}$ ICAR-Central Plantation Crops Research Institute, Regional Station, Kayamkulam 690 533, India \\ ${ }^{2}$ ICAR-Central Plantation Crops Research Institute, Kasaragod 671 124, India
}

As many as four exotic whiteflies of Neotropical origin have been reported from different coconut-growing regions in India in rapid succession in the last four years. The spiralling whitefly, Aleurodicus dispersus Russell was the earliest reported invasive species on coconut from Kerala in 1996. The rugose spiralling whitefly, Aleurodicus rugioperculatus Martin was first reported in 2016 followed by three species (Paraleyrodes bondari, Paraleyrodes minei and Aleurotrachelus atratus) in 2019. At present, all are found to coexist on coconut in South India. In such combined incidences, one species occupies the breeding and feeding niche of another under optimum weather parameters and attempts to displace one or more of its competitors. The Bondar's nesting whitefly, $P$. bondari is associated with rugose spiralling whitefly in most districts of Kerala and Tamil Nadu, whereas the nesting whitefly $P$. minei is interlinked with $A$. rugioperculatus in Kasaragod, Kerala, and also found to co-occur with the palm whitefly, $A$. atratus in Mandya, Karnataka. In Kayamkulam, Kerala, $P$. bondari, $P$. minei and $A$. rugioperculatus co-lived for a brief period during 2018. Due to the incursion and subsequent coexistence of these exotic whiteflies which share more or less the same niche with similar habits on coconut, it is imperative to identify them correctly for carrying out further studies on their bioecology, population dynamics and management. Hence an illustrated diagnostic account of these exotic whiteflies is given here to facilitate their visual identification by economic entomologists and field workers. The $C O I$ sequences of these exotic whiteflies are also given to enable rapid confirmation of the field diagnosis.

Keywords: Bioinvasion, coconut, coexistence, exotic whiteflies, field diagnosis.

Management of non-native pests in a new environment poses great challenges as they upset indigenous biodiversity, and usually multiply and spread rapidly in the absence of natural enemies. With the liberalization of international trade, introduction of planting material from different countries has paved the way for accidental entry of several exotic pests in the recent past, and the coconut

*For correspondence. (e-mail: joecpcri@gmail.com) system is no exception for such incursion. As many as four exotic whiteflies of Neotropical origin have entered India in just four years, starting with the rugose spiralling whitefly (Aleurodicus rugioperculatus Martin), which was reported in 2016 initially from Pollachi, Tamil Nadu and Palakkad, Kerala, and later expanded to all coconutgrowing regions in peninsular and North East India within a short $\operatorname{span}^{1}$. This incursion has been kept in check by the combined action of the exotic aphelinid parasitoid, Encarsia guadeloupae and in situ habitat conservation of the sooty mould scavenger beetle, Leiochrinus nilgiria$n u s^{2,3}$. Entry of two exotic nesting whiteflies (Paraleyrodes bondari and Paralyerodes minei) into Kerala in 2018 (refs 4, 5) and their coexistence with A. rugioperculatus have reduced the population density of $A$. rugioperculatus. Recently, in Mandya, Karnataka, palm whitefly (Aleurotrachelus atratus), another exotic species, has been reported; it was observed to be in consistent association with the Neotropical nesting whitefly (Paraleyrodes minei). Co-occurrence of these four exotic whiteflies with similar habits has often caused confusion in their identification, and further studies on their bioecology, natural enemies and management are hampered in the absence of accurate diagnostic support. Therefore, in this article, we provide a pictorial guide to all exotic whiteflies infesting coconut for their field-level identification by economic entomologists and extension workers supported by taxonomic characters. The $C O I$ sequences of these whiteflies are also given to enable rapid confirmation of their identities.

\section{Methodology}

Life stages of the exotic whiteflies were collected from three locations, viz. Kayamkulam, Pollachi and Mandya in the coconut-growing regions of South India.

\section{Molecular characterization}

Molecular characterization of the five whiteflies (Aleurodicus dispersus, A. rugioperculatus, P. bondari, P. minei and $A$. atratus) was done to facilitate their rapid identification by non-entomologists. Genomic DNA was isolated 
from the adults after they were morphologically identified. Primers LCO 14905'-GGTCAACAAATCATAAAGATATTGG-3' HCO 2198: 5'-TAAACTTCAGGGTGACCAAAAAATCA-3' synthesized in salt-free status (Eurofins Genomics India Pvt. Ltd) were used for the amplification of mitochondrial cytochrome $c$ oxidase subunit I (COI) gene ${ }^{6}$. Polymerase chain reaction (PCR) was carried out using a thermal cycler Techne Flexigene (Duxford, Cambridge, UK) ${ }^{7}$. PCR was carried out with an initial denaturation at $95^{\circ} \mathrm{C}$ for $5 \mathrm{~min}$ followed by 35 cycles of denaturation at $94^{\circ} \mathrm{C}$ for $1 \mathrm{~min}$, annealing at $55^{\circ} \mathrm{C}$ for $1 \mathrm{~min}$ and extension at $72^{\circ} \mathrm{C}$ for $1 \mathrm{~min} 30 \mathrm{sec}$. Final extension at $72^{\circ} \mathrm{C}$ for $10 \mathrm{~min}$ was done for endfilling. The products were analysed in $1.0 \%$ agarose gel. The amplicons obtained were purified from each reaction mixture using a PCR purification kit (Qiagen, Hilden, Germany). The purified products were then sequenced (AgriGenome Labs Pvt Ltd, Kochi).

\section{Results}

We recorded different life stages of $A$. atratus from the abaxial leaf surface on palm leaflets from Mandya. In many of the colonies of $A$. atratus, we could locate the adults and pupae of the nesting whitefly, $P$. minei mimicking the adults of $A$. atratus. This calls for a thorough distinction of all these species and the nature of their association. With the presence of pupae and adults of $P$. mine $i$ in the colony of $A$. atratus, at least some of the $A$. atratus colonies had nearly dismantled and collapsed. In many countries, feeding by $A$. atratus was found to cause necrotic lesions on palm leaflets and significant drop in nut yield as well. However, in Mandya, A. atratus colonies on palm leaflets coexisted with $P$. minei life stages, and this caused a kind of competitive interaction that probably reduced the aggressiveness of $A$. atratus coupled with favourable weather conditions such as uniform distribution of rainfall in the region during MayJuly 2019. Though the pupal colonies were intermixed, adult whiteflies were not co-living, but $P$. minei adults mostly rested on the colonies of $A$. atratus. In addition, we could observe a few colonies of rugose spiralling whitefly that were heavily parasitized by E. guadeloupae and replaced by $P$. minei and $A$. atratus. We could neither locate colonies of Bondar's nesting whitefly, $P$. bondari nor spiralling whitefly, A. dispersus in this study.

The guild of exotic whiteflies was found to vary in different coconut-growing regions of South India. Simultaneous occurrence of two nesting whiteflies ( $P$. bondari and $P$. minei) in association with $A$. rugiopercualtus was reported from Kayamkulam ${ }^{5}$, whereas $P$. minei and $A$. rugioperculatus were found together in Kasaragod, Kerala ${ }^{8}$. Furthermore, $P$. bondari and A. rugioperculatus cooccurred and in favourable weather condition could also reduce the pestiferous potential of rugose spiralling whi- tefly in Pollachi. This association of nesting whiteflies with rugose spiralling whitefly not only hindered the development of whiteflies, but also encouraged higher parasitism of E. guadeloupae on A. rugioperculatus. Cooccurrence of Bondar's nesting whitefly and Paraleyrodes psuedonaranjae on pond apple as well as $A$. rugioperculatus and $P$. bondari on mango was documented from Florida, USA 9 . In addition, coexistence of the nesting whitefly, P. minei and the woolly whitefly, Aleurothrixus floccosus (Maskell) was also recorded on citrus from Greece ${ }^{10}$. Further, in Coimbatore, Tamil Nadu, cooccurrence of two spiralling whiteflies (A. dispersus and A. rugioperculatus), two nesting whiteflies ( $P$. bondari and $P$. minei) and a new woolly whitefly, Aleurothrixus sp. was observed on guava (unpublished data).

Due to the overlapping of different whitefly species on the same niche, it is necessary to train extension workers and nursery workers in their field identification so that infested planting material in transit within a carton is identified accurately at species level. A brief account of the exotic whiteflies on coconut in South India is given below to facilitate their detection based on colony characters and diagnostic features.

\section{Aleurodicus dispersus Russell}

Spiral mode of egg-laying (Figure 1(1 a)) and covered with powdery mass, prominent projections on nymphs with two tail-like structures (Figure $1(\mathbf{1} b)$ ), convex pupa, non-corrugated operculum, blunt and tongue-like lingula (Figure $1(\mathbf{1} \boldsymbol{d})$ ), slender adult, adult $2.1 \mathrm{~mm}$ long, pure white with no markings on wings (Figure 1(1c)). Minor pest of coconut, polyphagous with guava being the preferred host ${ }^{11-13}$.

\section{Aleurodicus rugioperculatus Martin}

Spiral mode of egg-laying on palm parts (Figure 1(2a)), inconspicuous projections on nymphs with normally one tail-like structure (Figure 1(2 b)), convex pupa, rugose operculum, triangular and pointed lingula (Figure 1(2d)), adult robust, measuring $2.3 \mathrm{~mm}$, white with greyishbrown mottling/pattern on wings (Figure 1(2c)). Polyphagous, with coconut being the most preferred host ${ }^{1-14}$.

\section{Paraleyrodes bondari Peracchi}

Stalked eggs (Figure 1(3a)), nymphs flat with prominent silken threads from dorsum and marginal hairs (Figure $1(3 \mathrm{~b})$ ), pupa flat with flower-petal like compound pores, small adult measuring about $1.0 \mathrm{~mm}$ with $\mathrm{X}$-shaped markings on wings (Figure $1(\mathbf{3} c)$ ) resting in more or less clearly demarcated nests. Male genitalia (Figure 1(3d)) rod-like with anterior and posterior horns ${ }^{4,11,15}$. 


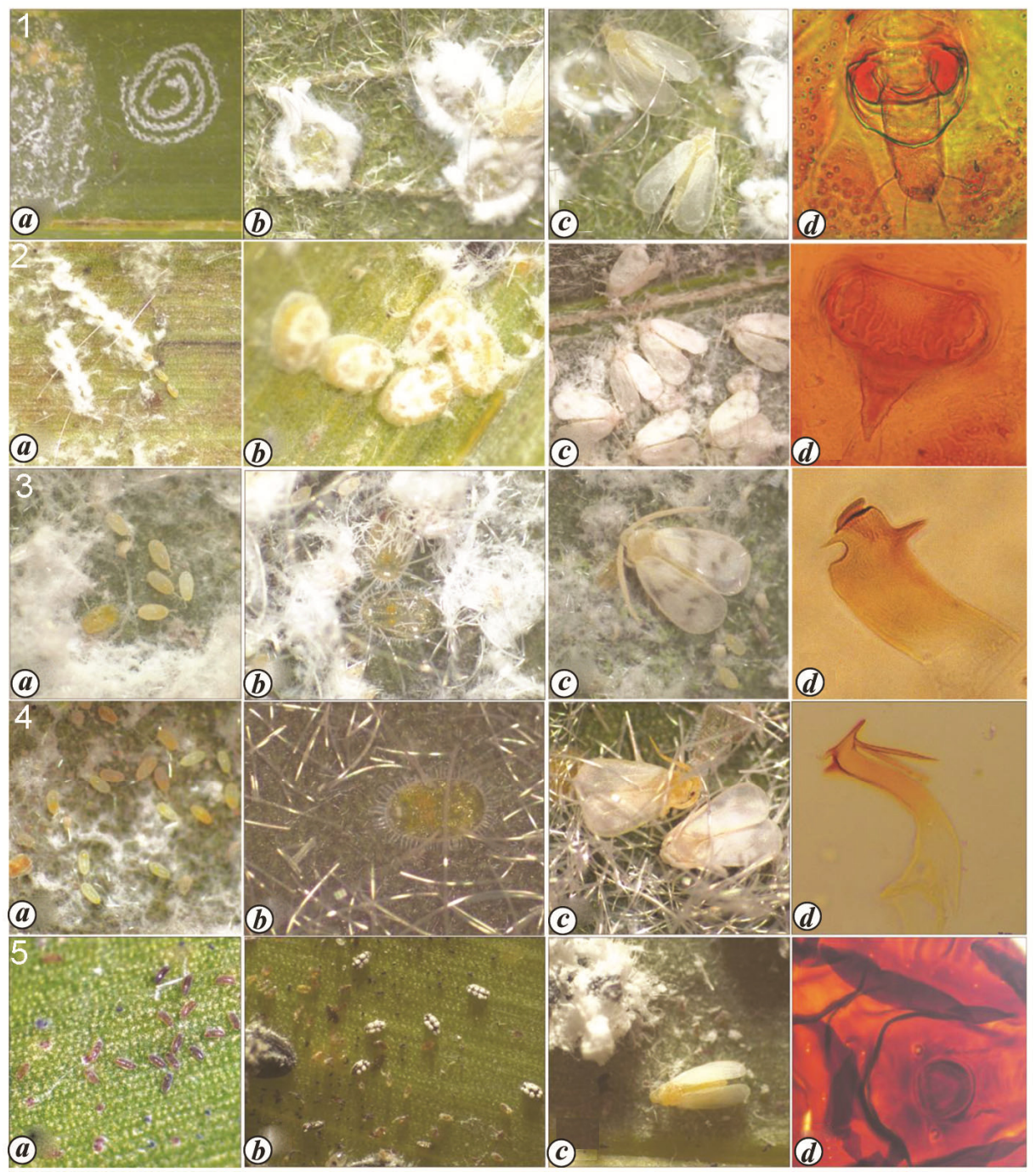

Figure 1. Identification features of five invasive whiteflies infesting coconut: (1) Aleurodicus dispersus: $\boldsymbol{a}$, Eggs; $\boldsymbol{b}$, nymphs with anal fluffs; $\boldsymbol{c}$, adult whiteflies; $\boldsymbol{d}$, Tongue-like lingula; (2) Aleurodicus rugioperculatus: $\boldsymbol{a}$, Eggs; $\boldsymbol{b}$, nymphs; $\boldsymbol{c}$, Adult whiteflies; $\boldsymbol{d}$, Rugose operculum with triangular lingula; (3) Paraleyrodes bondari: $\boldsymbol{a}$, Eggs; $\boldsymbol{b}$, nymphs; $\boldsymbol{c}$, Adult whitefly; $\boldsymbol{d}$, Male genitalia; (4) Paraleyrodes minei: $\boldsymbol{a}$, Eggs; $\boldsymbol{b}$, nymphs; $\boldsymbol{c}$, Adult whitefly; $\boldsymbol{d}$, Cock-head like male genitalia; (5) Aleurotrachelus atratus: $\boldsymbol{a}$, Eggs; $\boldsymbol{b}$, Nymphs; $\boldsymbol{c}$, Adult; $\boldsymbol{d}$, Interrupted sub-marginal fold near operculum.

\section{Paraleyrodes minei Iaccarino}

Stalked eggs (Figure 1(4a)), nymphs flat with less prominent silken threads from dorsum and marginal hairs (Figure 1(4 b), pupa flat with flower-petal like compound pores, small adult measuring about $1.0 \mathrm{~mm}$, devoid of markings on wings (Figure $1(\mathbf{4} \boldsymbol{c})$ ), rests in loosely constructed nests. Male genitalia (Figure 1(4d)) cock-head like $\mathrm{e}^{5,11}$.

\section{Aleurotrachelus atratus Hempel}

Elliptical, stalked eggs (Figure 1(5a), turn black before eclosion. Eight prominent white spots on nymphs (Figure $1(\mathbf{5} \boldsymbol{b})$ ) which later coalesce and partially cover the black body, marginal serrations on pupa, round lingula (Figure $1(\mathbf{5} \boldsymbol{d})$ ), sub-marginal fold interrupted at vasiform orifice. Adult longer than broad (Figure 1(5c)), wings held rooflike $^{16}$.

A pictorial depiction of the life stages and diagnostic characters of the five non-native whiteflies infesting coconut is given here to enable their easy and correct identification by economic entomologists and field-level plant protection workers (Figure 1), as these are found to coexist in many places in South India. This could be used as a ready reckoner by quarantine officials, other plant protection personnel and extension workers for on-site detection of these whiteflies. At present, except A. dispersus and $A$. rugioperculatus, the other whiteflies have a more limited presence in South India and this would be useful for those involved in field examination of non-native 


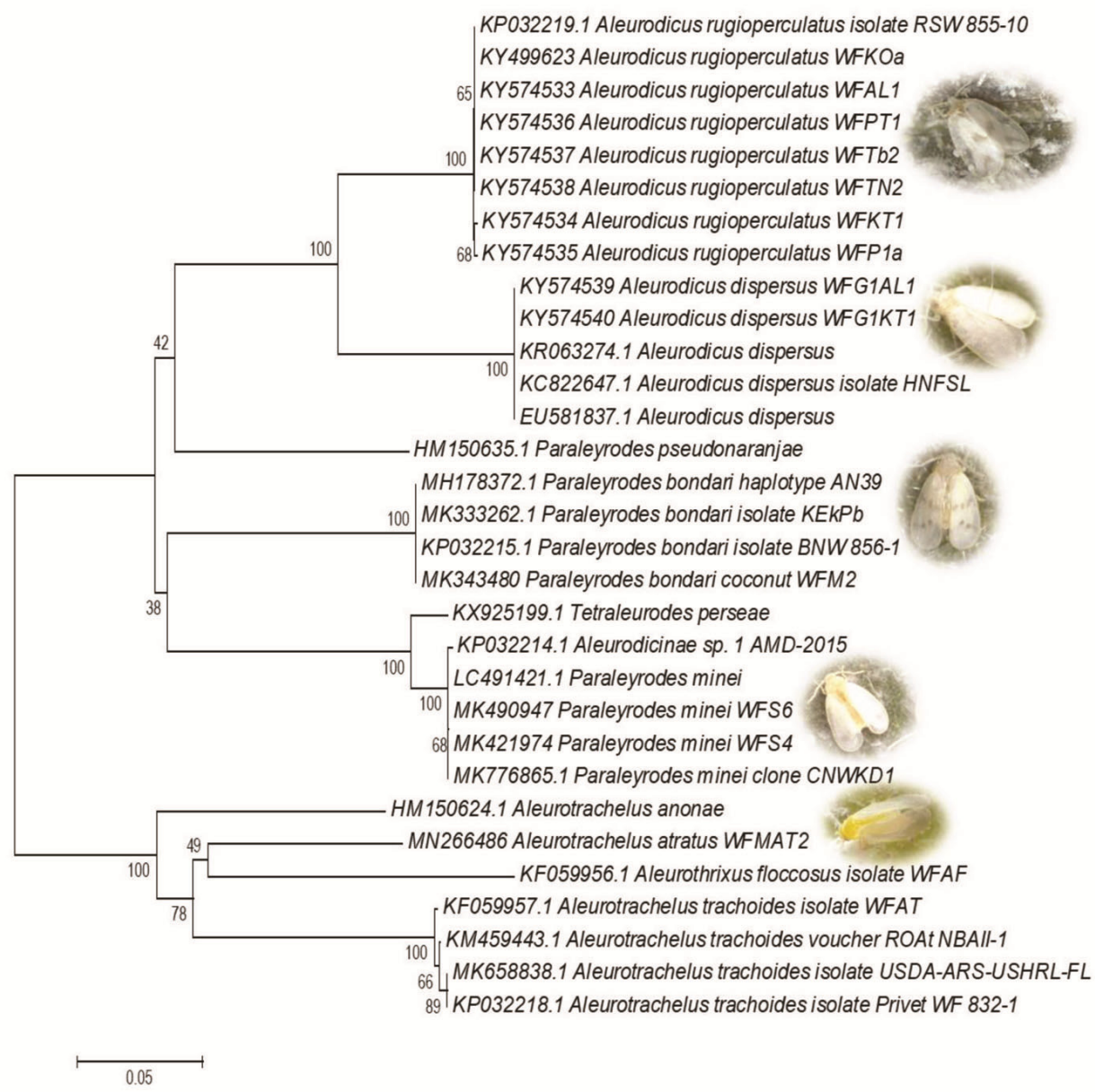

Figure 2. Phylogenetic tree and molecular lineage of invasive whiteflies infesting coconut in India

pests occurring on plant materials that are transported across regions, states, countries and continents. This study indicates the coexistence of whiteflies and likely competitive interactions among the species in different coconut-growing regions in India. Since more than one species of whitefly coexist in nature, correct identification would be of paramount importance and further confirmation could be accomplished through rapid molecular characterization.

It is remarkable that four whiteflies belonging to two taxonomically distinct subfamilies, Aleurodicinae (Aleurodicus spp., Paraleyrodes spp.) and Aleyrodinae (Aleurotrachelus sp.) are cohabiting on the same host plant in South Indian conditions. Molecular phylogenetic analysis also indicated the relative affinities of the five whitefly species (Figure 2). There are three groups in which the invasive whitefly species infesting coconut could converge, viz. Aleurodicus, Paraleyrodes and Aleurotrachelus (Aleurothrixus) groups. The first two groups are intrinsically more closely related than the Aleurotrachelus (Aleurothrixus) group, which is distantly placed demarcating the evolutionary significance of two subfamilies within family Aleyrodidae.
The aggressive competitiveness and coexistence of non-native whiteflies would be critically examined in the pest-inflicted zones for which correct identification of the exotic whitefly species and their molecular linkages are of paramount significance. The present study thus clearly identifies the whitefly species at field level and evolve management strategies to combat the pest. In association with other species in the same niche, the pest management options could be deferred while conservation biological control still holds the central fulcrum in the bio-suppression of invasive whiteflies in India.

Conflict of interest: The authors declare no potential conflict of interest.

1. Mohan Chandrika, Josephrajkumar, A., Singh, L. S. and Das Alpana, New distributional record of rugose spiralling whitefly on coconut in Kamrup and Nalbari districts of Assam. Indian Coconut J., 2018, 61(4), 19-21.

2. Josephrajkumar, A. et al., Discovery of a sooty mould scavenging beetle, Leiochrinus nilgirianus Kaszab (Coleoptera: Tenebrionidae) on coconut palms infested by the invasive rugose spiralling whitefly, Aleurodicus rugioperculatus Martin (Hemiptera: 
Aleyrodidae). Phytoparasitica, 2018, 46(1), 57-61; doi:10.1007/ s12600-017-0635-5.

3. Josephrajkumar, A., Mohan Chandrika, Prathibha, P. S., Rajkumar, Nalinakumari, T. and Nair, C. P. R., Pest dynamics and suppression strategies. In The Coconut Palm (Cocos nucifera Linn.) Research and Development Perspectives (eds Nampoothiri, K. U. K. et al.), Springer Nature, Singapore, 2018, pp. 557-634.

4. Josephrajkumar, A., Mohan Chandrika, Babu Merin, Krishna Arya, Krishnakumar, V., Hegde Vinayaka and Chowdappa, P., First record of the invasive Bondar's nesting whitefly, Paraleyrodes bondari Peracchi on coconut from India. Phytoparasitica, 2019, 47(3), 333-339; doi.org/10.1007/s12600-019-00741-2.

5. Mohan Chandrika, Josephrajkumar, A., Babu Merin, Krishna Arya, Prathibha, P. S., Krishnakumar, V. and Hegde Vinayaka, Non-native Neotropical nesting whitefly, Paraleyrodes minei Iaccarino on coconut palms in India and its co-existence with Bondar's nesting whitefly, Paraleyrodes bondari Peracchi. Curr. Sci., 2019, 117(3), 515-519; doi:10.18520/cs/v117/i3/515-519.

6. Folmer, O., Black, M., Hoeh, W., Lutz, R. and Vrijenhoek, R., DNA primers for amplification of mitochondrial cytochrome $c$ oxidase subunit I from diverse metazoan invertebrates. Mol. Mar. Biol. Biotechnol., 1994, 3(5), 294-299.

7. Sambrook, J. and Russell, D. W., Molecular Cloning: A Laboratory Manual, Cold Spring Harbor Laboratory, New York, USA, 2001, 3rd edn.

8. Sujithra, M., Rajkumar, Prathibha, V. H., Hegde Vinayaka and Poorani, J., Occurrence of nesting whitefly, Paraleyrodes minei Iaccarino (Hemiptera: Aleyrodidae) in India. Indian J. Entomol., 2019, 81(3), 507-510.

9. Dickey, A. M., Stocks, I. C., Smith, T., Osborne, L. and McKenzie, C. L., DNA barcode development for three recent exotic whitefly (Hemiptera: Aleyrodidae) invaders in Florida. Fla. Entomol., 2015, 9, 473-478.

10. Kalaitzaki, A. P., Tasgkarakis, A. E. and Ilias, A., First record of nesting whitefly, Paraleyrodes minei, in Greece. Entomol. Hellen, 2016, 25, 16-21.
11. Martin, J. H., Whiteflies of Belize (Aleyrodidae: Hemiptera). Part I-Introduction and account of the subfamily Aleurodicinae Quaintance \& Baker. Zootaxa, 2004, 681, 1-113.

12. Martin, J. H., Mifsud, D. and Rapisarda, C., The whiteflies (Hemiptera: Aleyrodidae) of the Europe and the Mediterranean Basin. Bull. Entomol. Res., 2000, 90, 407-448.

13. Shanas, S., Job Joseph, Joseph Tom and Anju Krishnan, G., First report of the invasive rugose spiraling whitefly, Aleurodicus rugioperculatus Martin (Hemiptera: Aleyrodidae) from the Old World. Entomon, 2016, 41(4), 365-368.

14. Sundararaj, R. and Selvaraj, K., Invasion of rugose spiraling whitefly, Aleurodicus rugioperculatus Martin (Hemiptera: Aleyrodidae): a potential threat to coconut in India. Phytoparasitica, 2017, 45(1), 71-74; doi:10.1007/s12600-017-0567-0.

15. Peracchi, A. L., Doisaleirodideospragas de Citrus no Brasil (Homoptera, Aleyrodidae). Arq. Mus. Nac., Rio de J., 1971, 54, $145-151$.

16. Selvaraj, K., Sundararaj, R. and Sumalatha, B. V., Invasion of the palm infesting whitefly, Aleurotrachelus atratus Hempel (Hemiptera: Aleyrodidae) in the Oriental region. Phytoparasitica, 2019, 47(3), 327-332; doi:org/10.1007/s12600-019-00742-1.

ACKNOWLEDGEMENTS. We thank the Indian Council of Agricultural Research, New Delhi for the grant-in-aid through an ICARCPCRI Institutional Project. We also thank Dr J. Poorani (ICARNational Research Centre on Banana, Tiruchirappalli) for a critical review of the manuscript.

Received 15 January 2020; revised accepted 11 August 2020

doi: $10.18520 / \mathrm{cs} / \mathrm{v} 119 / \mathrm{i} 7 / 1101-1105$ 